\title{
Morphological Ghanges and Resistance induced in Saccharomyces pastorianus by the antibiotic cycloheximide
}

\author{
BY K. GUNDERSEN AND 'T. WADSTEIN \\ Botanical Institute, Gothenburg University, Sweden
}

(Received 29 August 1961)

\section{SUMMARY}

The growth of Saccharomyces pastorianus was $50 \%$ inhibited by 0.013 p.p.m. cycloheximide, and completely inhibited by $0 \cdot 100$ p.p.m. in liquid medium after $24 \mathrm{hr}$. at $28^{\circ}$. At subinhibitory concentrations of cycloheximide abnormally large cells and cell aggregates were formed, probably as a result of interference by cycloheximide with the synthesis of structural cell-wall materials. When $S$. pastorianus was grown in media with successively higher concentrations of cycloheximide partially resistant organisms were developed. These did not form aggregates and giant cells in the presence of cycloheximide, but on back inoculation to cycloheximide-free media they were 'slow growers' and formed small colonies on nutrient agar. After a few transfers on cyclo heximide-free media the resistant organisms reverted to the normal 'fast growing' type. The resistance to cycloheximide was not the result of any acquired ability to decompose or inactivate the compound.

\section{INTRODUCTION}

The growth inhibitory effect and the action mechanism of cycloheximide (actidione) on Saccharomyces pastorianus was investigated by Whiffen (1948), Coursen \& Sisler (1960) and others. However, no descriptions are given in these papers of the morphology of organisms grown at subinhibitory concentrations of the compound. Since it was found in this laboratory that the action of cycloheximide on the metabolism of $S$. pastorianus was reflected in anomalies in the growth and reproduction of sensitive organisms it was thought useful to give a description of this secondary effect of cycloheximide. Some observations on induced resistance of $S$. pastorianus towards cycloheximide will also be described.

\section{METHODS}

The organism used was Saccharomyces pastorianus Hansen, strain ATCC 2366. Stock cultures were maintained on a solidified yeast extract medium ( $\mathrm{pH} \mathrm{6.0)}$ : glucose, 10 g.; yeast extract (Difco), 2.5 g.; $\mathrm{KH}_{2} \mathrm{PO}_{4}, 1 \mathrm{~g}$.; Bacto-agar (Difco) $20 \mathrm{~g}$.; distilled water to $1000 \mathrm{ml}$. This medium, and a liquid medium of the same $\mathrm{pH}$ value and composition, but without the agar, was used for all the experiments. The media were sterilized by autoclaving at $115^{\circ}$ for $15 \mathrm{~min}$. and the cultures incubated at $28^{\circ}$. Unless otherwise stated all cultures were static. 
Stock solutions of cycloheximide ( $\beta$-(2-(3,5-dimethyl-2-oxo-cyclohexyl)-2-hydroxyethyl)-glutarimide; synonym: actidione) were prepared by dissolving $0 \cdot 25 \mathrm{~g}$. pure cycloheximide (obtained from The Upjohn Company, Kalamazoo, U.S.A.) in $5 \mathrm{ml}$. ethanol and diluting th s to $100 \mathrm{ml}$. with $\mathrm{M} / 15 \mathrm{KH}_{2} \mathrm{PO}_{4}$. The 2500 p.p.m. solution was sterilized by filtration and stored at $4^{\circ}$. Fresh solutions were made about every 4 weeks. Dilutions were always made in sterile $\mathrm{M} / 15 \mathrm{KH}_{2} \mathrm{PO}_{4}$ and not more than $0.1 \mathrm{ml}$. was added to $5 \mathrm{ml}$. liquid medium or to $25 \mathrm{ml}$. of solid medium to give the final concentration.

A bio-assay of cycloheximide was made by placing $13 \mathrm{~mm}$. filter paper disks (pads) moistened with solutions of known cycloheximide concentration on the surface of $15 \mathrm{ml}$. agar medium containing about $10^{4}$ Saccharomyces pastorianus organisms. These organisms (fror a $24 \mathrm{hr}$. culture) had been suspended in a larger batch of melted agar cooled to $45-50^{\circ}$ before they were pipetted out into sterile Petri dishes. After $24 \mathrm{hr}$. of incubation the inhibition zones were measured. Within the concentration range of 0.5-10 p.p.m. cycloheximide the diameters of the inhibition zones were proportional to $\log$ concentration. The cycloheximide contents of unknown samples we:e determined by directly reading their inhibition zones after proper incubation.

Turbidimetric readings were made at wavelength $550 \mathrm{~m} \mu$ in a Beckman model B spectrophotometer. The numbers of organisms $/ \mathrm{ml}$. corresponding to optical densities between 0.075 and 0.500 were che ked by counting in a Buerker blood-cell counting chamber.

\section{RESUL'TS}

\section{Growth inhibition in liquid media}

With an inoculum giving $10^{3}$ via sle organisms $/ \mathrm{ml}$. medium at zero time the growth of Saccharomyces pastorianus in presence of increasing concentrations of cycloheximide was determined turbidimetrically after incubation for $24 \mathrm{hr}$. (Fig. 1). The effective dose for $50 \%$ inhibition (ED 50) was 0.013 p.p.m. No growth occurred at $0 \cdot 1$ p.p.m. cycloheximide.

The sediment of organisms, formed in cultures containing 0.025 p.p.m. and higher concentrations of cycloheximide differed from normal sediments in being flocculent rather than compact and without an entire edge. This different appearance of the sediment pointed towards some anomaly in the growth of the organism in media containing cycloheximide. Microscopical examination of the flocculent sediment revealed that most of the organisms occurred in aggregates containing from 5 to 30 organisms sticking together. Although difficult to make out with certainty it seemed that the aggre gates had formed by repeated budding without complete separation of the daught r cells in the same way as in the formation of a pseudomycelium. The aggregated cells showed considerable differences in size, some (the oldest?) having a diameter three or more times the diameter of normal cells (Pl. 1, fig. 2-6).

The internal structure of these cells sometimes appeared more granulated than normal, grains apparently being present both in vacuoles and in the cytoplasm. In several of the giant cells the vacuole made up nearly the whole cell volume, the protoplasm being restricted to a fairly thin layer between the vacuole and the cell wall. In some cells the cell wall seemed to have been damaged in some way, giving 
the cell a shrivelled surface. Sometimes no cell wall could be seen at all, the cell appearing naked (Pl. 1, fig. 3). In media containing cycloheximide cells of normal size and appearance were also seen mixed up with the cell aggregates and giant cells, especially on prolonged incubation (2-3 days) These 'normal' cells probably were cells resistant to cycloheximide as evidenced in experiments described later.

\section{Aggregation and cell morphology at subinhibitory and inhibitory concentrations of cycloheximide}

A sample (0.05 ml.) of a $24 \mathrm{hr}$. old culture of Saccharomyces pastorianus was used as inoculum for liquid media containing no cycloheximide, or 0.06 p.p.m. or 1 p.p.m. cycloheximide. These media were incubated for $\mathbf{2 4} \mathrm{hr}$. and examined by the microscope. As expected, cells grown in the presence of 0.06 p.p.m. cycloheximide showed the usual aggregation and swellings previously described. No growth occurred in the 1 p.p.m. media but it was observed that the inoculum cells were affected. As compared with the number of aggregates found with subinhibitory concentrations of cycloheximide few and smaller aggregates had formed, but most of the intact cells were considerably enlarged. In many cells the cell wall was ruptured, usually at one point only (the budding scar?) and more or less of the cell contents had been emptied into the surroundings (Pl. 1, figs. 5, 6). Several shrivelled cell envelopes were seen and groups of grains and diffuse material showed that some of the cells had been more or less emptied.

Although 1 p.p.m. cycloheximide inhibits the growth of Saccharomyces pastorianus metabolic processes still proceed at a high rate when nutrients are available (Coursen \& Sisler, 1960). As it was of interest to know whether cycloheximide affected the cell size and morphology, irrespective of metabolic activity, the above experiment was repeated with starved cells suspended in a nutrient-free medium. Portions of $24 \mathrm{hr}$. cultures were centrifuged and the sediment washed several times with $\mathrm{m} / 15$ phosphate $(\mathrm{pH} 4 \cdot 5)$. After resuspension the organisms were starved at $28^{\circ}$ for $24 \mathrm{hr}$. before cycloheximide, 1 and 10 p.p.m., was added. At intervals the sediments of organisms were examined under the microscope. During a $30 \mathrm{hr}$. period no swellings or other abnormal changes were seen. It was therefore concluded that cycloheximide had no destructive effect on preformed cell walls.

\section{Strength of the cell wall of cycloheximide-grown cells}

The purpose of the following experiment was to find out whether the cell wall of cycloheximide-grown organisms had been weakened during contact with the compound. If this were true it might be expected that the cells (or at least some cells) would burst because of increased turgor when washed and transferred to distilled water. Samples $(15 \mathrm{ml}$.) of liquid medium without and with addition of $0 \cdot 05$ p.p.m. cycloheximide were inoculated with a fairly heavy suspension $\left(5 \times 10^{7}\right.$ organisms) prepared from a $24 \mathrm{hr}$. culture of Saccharomyces pastorianus on agar medium. After $\mathbf{2 4} \mathrm{hr}$. the actual cell numbers were determined in a blood-cell counting chamber. Samples $(10 \mathrm{ml}$.) of the cultures were simultaneously centrifuged at $3000 \mathrm{rev} . / \mathrm{min}$. for $15 \mathrm{~min}$., the supernatant fluid carefully removed and the sediment washed and centrifuged twice with $10 \mathrm{ml}$. distilled water. After final resuspension in $10 \mathrm{ml}$. distilled water the cell numbers were again counted in the blood-cell counting chamber. In several experiments of this type no significant 
decrease in cell number was ever found. Negative results were also obtained with 1 p.p.m. cycloheximide. It was also seen that the volume of cycloheximide-grown cells did not increase further after replacement of the nutrient medium by water, as might have been the case if cycloheximide caused a softening of the otherwise rigid cell wall.

\section{Effect of cyclohexinide on growth on solid medium}

A sample $(0.05 \mathrm{ml}$.) of a suspension of Saccharomyces pastorianus containing about 150 organisms was spread on the surface of $25 \mathrm{ml}$. agar plates containing different amounts of cycloheximide. The plates were incubated at $28^{\circ}$ and the colonies counted and measured daily durings 14 days. A lag in the onset of growth resulted

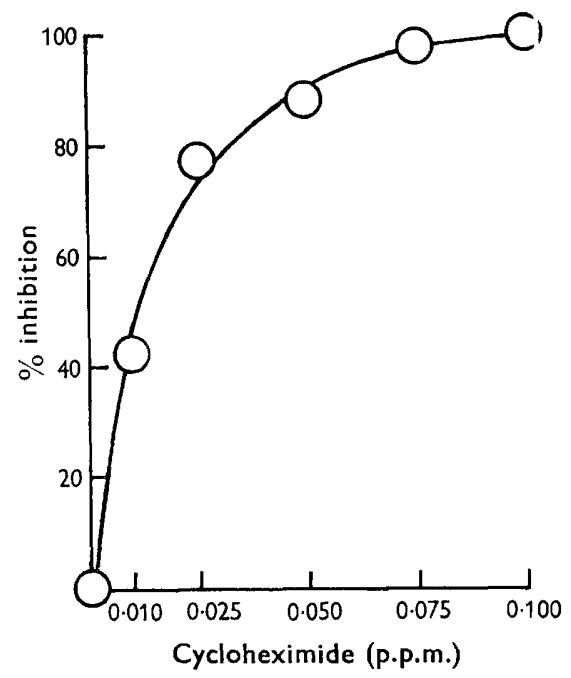

Fig. 1

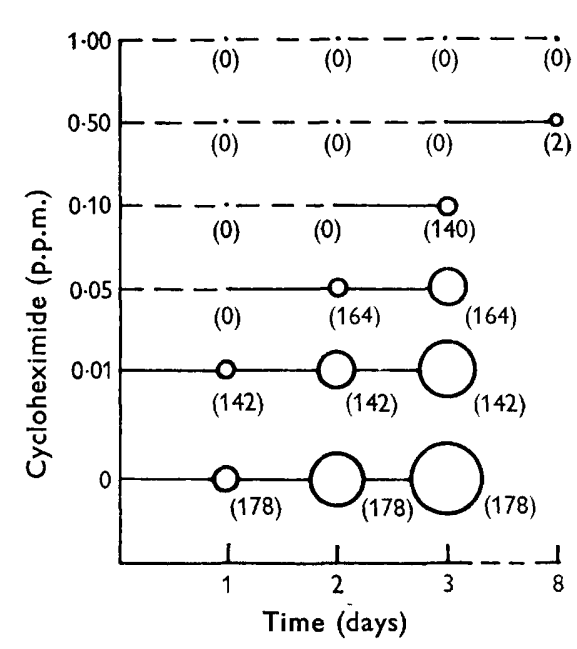

Fig. 2

Fig. 1. Growth of Saccharomyces pastorianus in liquid yeast extract medium with varying amounts of cycloheximide. $24 \mathrm{hr}$., $28^{\circ}$.

Fig. 2. Growth of Saccharomyces pa torianus on yeast extract agar with varying amounts of cycloheximide. The circles show the sizes of the colonies at different times and different concentrations of cyclohexirnide. Figures in brackets are the total number of colonies on the agar plates.

when cycloheximide was incorporited in the media, but the final colony numbers were not decreased within the concentration range 0.01-0.1 p.p.m. With 0.5 p.p.m. cycloheximide not more than $2 \%$ of the inoculum organisms gave rise to colonies which were visible only after an appreciable time (8-10 days). When examined microscopically, cells from these colonies were seen to be considerably enlarged, but aggregates were not formed. With 1 p.p.m. cycloheximide in the media no colonies were formed within 4 weeks. The relative growth of $S$. pastorianus on solid media is illustrated diagrammatically in Fig. 2.

\section{Isolation and growth of cycloheximide-resistant organisms}

Saccharomyces pastorianus was allowed to grow for $72 \mathrm{hr}$. in liquid medium without and with addition of 0.05 p.p. m. cycloheximide. At the end of the incubation period the cultures were diluted in sterile saline to about $10^{3}$ organisms $/ \mathrm{ml}$. and 
$0.05 \mathrm{ml}$. spread on agar medium without any cycloheximide. After $48 \mathrm{hr}$. of incubation the plates were examined. It was seen that colonies of two different sizes had formed on the plates which had been inoculated with material from the medium containing cycloheximide. The larger colonies corresponded in size and appearance to those formed on plates inoculated with organisms from cycloheximide-free media. The colonies of the second type had the same white colour and regular smooth appearance as the larger colonies, but were definitely smaller in size (Pl. 1, fig. 7).

The three kinds of colonies were picked and streaked on agar medium. After incubation for $\mathbf{2 4} \mathrm{hr}$. cell suspensions were prepared from the different growths and $0.05 \mathrm{ml}$. samples pipetted into $5 \mathrm{ml}$. lots of liquid medium containing different amounts of cycloheximide. Growth in these media was determined turbidimetrically after 24 and $48 \mathrm{hr}$. of incubation at $28^{\circ}$ (Table 1 ). The cells of the smaller colonies showed slower growth also in the liquid cycloheximide-free medium. In none of the media was there any difference in growth between normal organisms and the organisms of the larger colonies. But in the media containing 0.05 p.p.m. and higher concentrations of cycloheximide the growth of the small-colony type organisms was less inhibited than that of the other two.

Table 1. Saccharomyces pastorianus: growth in liquid yeast extract medium with different amounts of cycloheximide

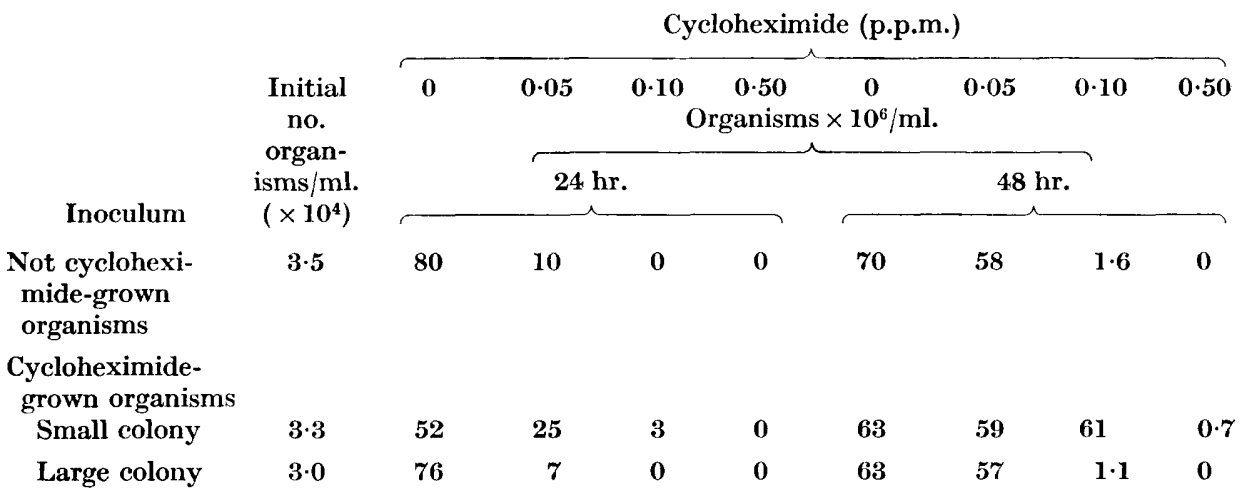

This experiment showed that in liquid medium containing 0.05 p.p.m. cycloheximide organisms are developed which readily became resistant to cycloheximideconcentrations 2-10 times higher than the original concentration. These resistant organisms gave rise to small colonies on cycloheximide-free media. In the same cultures viable non-resistant organisms, resembling normal ones in growth rate and response to cycloheximide, were also present. Whereas normal organisms and nonresistant cycloheximide-grown organisms when exposed to 0.05 or $0 \cdot 10$ p.p.m. cycloheximide displayed the usual picture of swollen cells and aggregates in abundance, the resistant organisms were of normal size and appearance and did not form aggregates in the presence of $0 \cdot 10$ p.p.m. cycloheximide. 


\section{The persistence of cyclohe:imide in cultures of resistant organisms}

Although it seemed not very probable that cycloheximide-resistant organisms had been enzymatically adapted to decompose or inactivate cycloheximide this possibility could not be entirely r sled out. Therefore, an experiment was carried out in which the cycloheximide :oncentration was determined before and after growth of resistant organisms. The quantitative determination of cycloheximide was made by the bio-assay described in Methods. However, as the range most reliable for assay is between 2 and 5 p.p.m. cycloheximide it was necessary to increase further the resistance of the cycloheximide-resistant organisms obtained in earlier experiments. This was done by inoculation into liquid medium containing 1 p.p.m. cycloheximide from the 6.5 p.p.m. culture. When good growth (about $10^{6}$ organisms/ml.) had occurred in the higher concentration, inoculation was made into 2 p.p.m. cycloheximide and so on, until the organism would grow in 5 p.p.m. cycloheximide. The time needed to obtain good growth was longer the higher the concentration. Thus, to go from 4 to 5 p.p.m. 6 days were required, although the time needed to obtain good growth in subcultures of the same concentrations of cycloheximide decreases with the number of subcultures.

Saccharomyces pastorianus which had in this way been trained to grow in the presence of 5 p.p.m. cycloheximide was now inoculated into liquid medium $(25 \mathrm{ml}$. in conical flasks) containing 3 p.p.m. cycloheximide. Experiments were made with static cultures incubated at $28^{\circ}$ and with cultures at $25^{\circ}$ on a reciprocal shaker. After growth for 7 days in 3 p.p m. cycloheximide the cultures were centrifuged and the cycloheximide content of the supernatant culture fluid tested against uninoculated medium initially containing the same amount of cycloheximide. Controls were taken from cycloheximide-free media, some uninoculated, and some inoculated with cycloheximide-resistant and non-resistant organisms. No removal of cycloheximide from the cultures of cycloheximide-resistant organisms was found in any of these experiments. This negative result is evidence that acquired resistance to cycloheximide does not imply enzymic adaptation or any other kind of inactivation of cycloheximide by $S$, pastorianus.

\section{DISCUSSION}

Reasons for the formation of giant cells in Saccharomyces pastorianus in the presence of cycloheximide might include: (1) cycloheximide has dissolved or softened the preformed rigid cell walls so that these will no longer resist the turgor pressure of the protoplast; (2) by altering the cellular metabolism or the permeability of the cell membranes cyclohexinide has caused an elevation of the osmotic value of the cells, which again has resulted in increased turgor pressure followed by a reversible swelling; (3) cycloheximide has affected the synthesis of structural cell wall materials, resulting in irreversible enlargement of the 'cell wall'.

The results of the present work give little support to the first two of these hypotheses. Cycloheximide caused morphological changes only in growing organisms and in organisms which had not been deprived of reserve nutrients, but not in starved organisms suspended in a nutrient-free medium. The same results were obtained with the filamentous fungus Fomes annosus in which cycloheximide has 
a similar effect on the cell wall (Gundersen, 1961). If cycloheximide had a dissolving effect on preformed cell walls it might be expected that this effect would also be obtained with resting starved cells.

If the second explanation of the giant cell formation were correct it might be expected that these cells would split or expand further on being transferred from a medium of relatively high osmotic value (the culture fluid) to a medium of zero osmotic value (distilled water); this was not the case. The second hypothesis also presupposes a considerable resilience of the cell wall. It may be calculated that the surface of the largest cells increased 10-fold as a result of the cycloheximide treatment. Such a degree of resilience could hardly be expected in the cell walls of a yeast.

The last hypothesis, an effect of cycloheximide on the synthesis of cell wall materials, has not been proved nor disproved in this work. However, it is supported by the observation that when cycloheximide-grown organisms are plasmolysed in $0.5 \mathrm{~m}$ sucrose only the protoplast contracts, whereas the cell wall preserves its original size.

The formation of cell aggregates in cycloheximide-grown Saccharomyces pastorianus appears to be a result of the cycloheximide effect on the cell wall. In the phasecontrast microscope it could be seen that the cytoplasmic strands connecting neighbouring cells in these aggregates usually were much thicker than normal. Also the budding scars seemed to be enlarged. These changes suggest that the severance of cells was rendered difficult. However, the circumstances relating to cell division in cycloheximide-grown $S$. pastorianus probably are more complicated than this. Kerridge (1957, 1958) showed that in $S$. mandshuricus and in $S$. carlsbergensis cycloheximide inhibited the synthesis of protein and deoxyribonucleic acid at minimum growth-inhibitory concentrations. If this effect is also valid for $S$. pastorianus cycloheximide must have a profound influence on the whole process of cell division, including the severance of the cells.

Organisms resistant to cycloheximide always develop in media containing cycloheximide. This has been observed by Whiffen (1948) in Saccharomyces pastorianus and by Monreal (1961) in S. cerevisiae var. ellipsoideus. Resistance to cycloheximide was also obtained in Fomes annosus (Gundersen, 1962) and in Sclerotinia fructicola and S. laxa (Grover \& Moore, 1961). In these organisms the resistance was obtained slowly by transfer of cell material (or mycelium) from medium of lower cycloheximide concentration to medium of slightly higher concentration. No absolute tolerance towards cycloheximide was obtained in any of these cases. In $S$. pastorianus even prolonged growth and serial subcultures in 5 p.p.m. cycloheximide did not produce organisms with a growth rate as high as that of non-resistant organisms. With Fomes annosus the upper limit of tolerance was found at about 10 p.p.m. cycloheximide. This sluggishness in the formation of resistant organisms, and the absence of formation of a cycloheximide-splitting enzyme, makes it seem probable that many factors are involved. Monreal (1961) used the term 'modification' for resistant organisms formation in $S$. cerevisiae. But it remains to be explained what is implied in this term.

This investigation was supported by the Swedish Natural Science Research Council. 


\section{REFERENCES}

Coursen, B. W. \& Sisuer, H. D. (1960). Effect of the antibiotic, cycloheximide, on the metabolism and growth of Saccharcmyces pastorianus. Amer. J. Bot. 47, 541.

Grover, R. K. \& MOORE, J. D. (1961). Adaptation of Sclerotinia fructicola and Sclerotinia laxa to higher concentrations of fungicides. Phytopathology, 51, 399.

Gundersen, K. (1961). Cycloheximide, the active substance in Streptomyces griseus antagonism against Fomes annosus. Acta Horti gothoburg. 24, 1.

Gundersen, K. (1962). Adaptation of Fomes annosus to the antibiotic cycloheximide. Acta Horti gothoburg. 25 (in the Press).

KERRIDGe, D. (1957). The effect of actidione on protein and nucleic acid synthesis in Saccharomyces mandshuricus. J. gen. Microbiol. 16, v.

Kerridge, D. (1958). The effect of actidione and other antifungal agents on nucleic acid and protein synthesis in Saccharomyces carlsbergensis. J. gen. Microbiol. 19, 497.

Monreal, K. (1961). Die Wirkung von Actidion auf Saccharomyces cerevisiae var. ellipsoideus. Angew. Bot. 35, 24.

Whiffen, A. J. (1948). The production, assay, and antibiotic activity of actidione, an antibiotic from Streptomyces griseus. J. Bact. 56, 283.

\section{EXPLANATION OF PLATE 1}

Effect of cycloheximide on Saccharomyces pastorianus. Figs. 1-6 are phase contrast micrographs.

Fig. 1. Normal organisms, $72 \mathrm{hr} .28^{\circ}$.

Fig. 2. Cell aggregate with enlarged cells formed during growth in the presence of 0.05 p.p.m. cycloheximide, $72 \mathrm{hr} . \mathbf{2 8}^{\circ}$.

Fig. 3. Cell aggregate formed in 0.05 p.p.m. cycloheximide with giant cell containing one large vacuole $(a)$, and lysed cell $(b), 72 \mathrm{hr} .28^{\circ}$.

Fig. 4. Cell aggregate and single giant cell formed in 1 p.p.m. cycloheximide, $48 \mathrm{hr}$. $28^{\circ}$.

Fig. 5. Cell aggregate formed in 1 p.p.mı. cycloheximide. One cell has lysed $(c)$, or the mass of cytoplasm comes from neighbouring cell $(d), 48 \mathrm{hr} .28^{\circ}$.

Fig. 6. Shrivelled and punctured cells with extruding cytoplasm from 1 p.p.m. cycloheximide, $48 \mathrm{hr} .28^{\circ}$.

Fig. 7. Colonies on yeast extract agar cleveloped from cells previously grown in liquid medium containing 0.05 p.p.m. cycloheximide. Small colonies: cells resistant to cycloheximide; large colonies: cells not resistant to cyclohexinide. 7 days $28^{\circ}$. 
Journal of General Microbiology, Vol. 28, No. 2

Plate 1

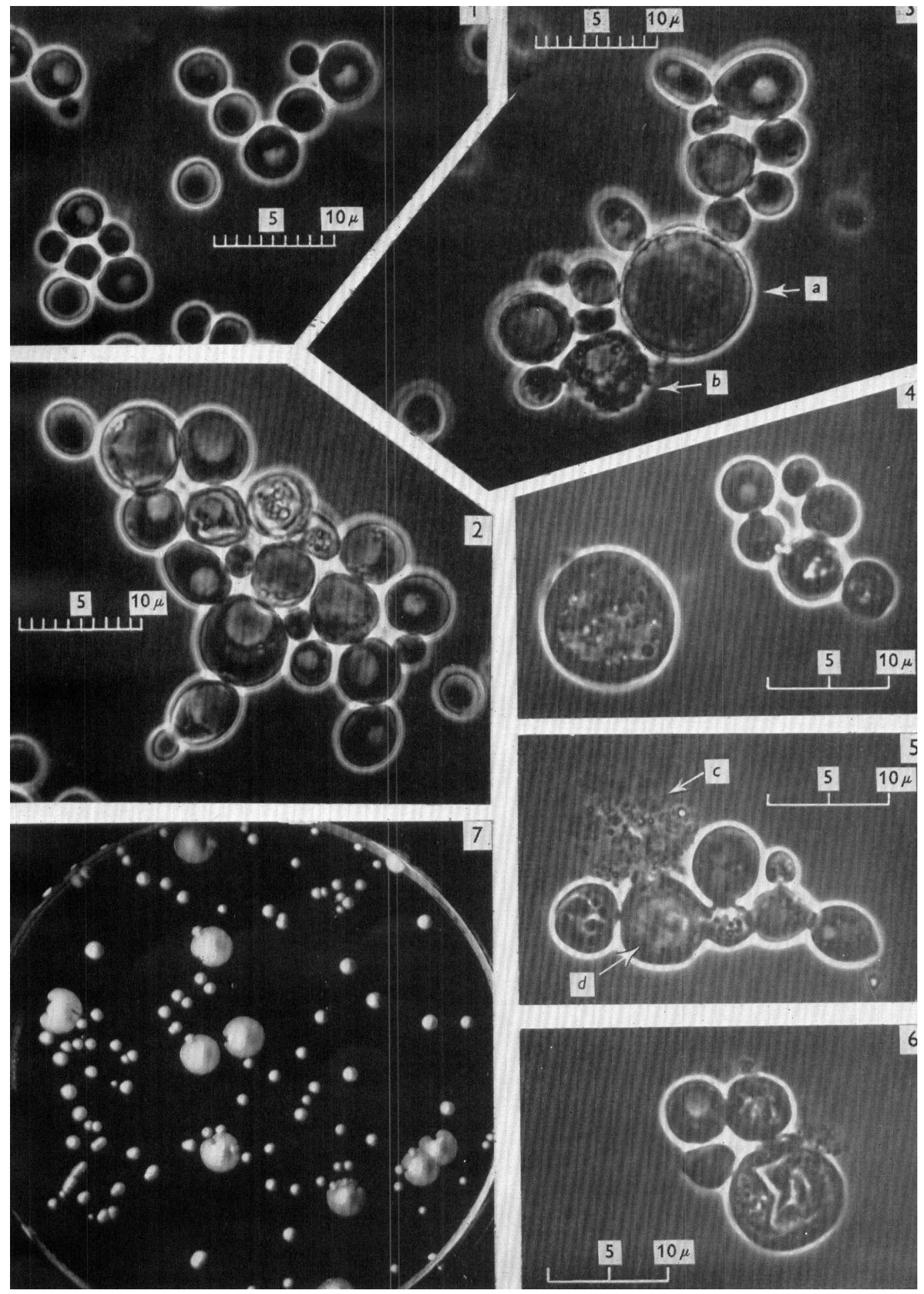

K. GUNDERSEN AND T. WADSTEIN

(Facing $p .332$ ) 